\title{
Racismo e Políticas Afirmativas: Evidências do Modelo da Discriminação Justificada ${ }^{1}$
}

\author{
João Gabriel Modesto ${ }^{2}$ \\ Centro Universitário de Brasília \\ Universidade Estadual de Goiás \\ Ana Caroline Minelli \\ Maria Paula Fernandes \\ Matheus Rodrigues \\ Ravena Bufolo \\ Rodolfo Bitencourt \\ Ronaldo Pilati \\ Universidade de Brasília
}

\begin{abstract}
RESUMO - O Modelo da Discriminação Justificada postula que o uso de justificativas exerce um importante papel na compreensão da discriminação. No presente estudo, testamos o MDJ no contexto da discriminação a estudantes que ingressaram na universidade por cotas raciais. Participaram do estudo 182 estudantes universitários, em sua maioria mulheres, que ingressaram na universidade pela ampla concorrência. Os participantes responderam a medidas de preconceito, de discriminação, de percepção de ameaça real e foram alocados em uma de três condições experimentais: valorização das cotas, ameaça real e controle. Verificou-se que a percepção de ameaça real exerceu um papel de mediação na relação entre preconceito e discriminação, independente da condição experimental, indicando o potencial explicativo do MDJ para compreensão da discriminação a cotistas.
\end{abstract}

Palavras-chave: preconceito, discriminação, Modelo da Discriminação Justificada, políticas afirmativas

\section{Racism and Affirmative Action: Evidence for the Justified Discrimination Model}

\begin{abstract}
The Justified Discrimination Model postulates that the use of justifications exerts an important role in understanding discrimination. In this study, we tested the JDM in the context of discrimination against students who were admitted to the university through affirmative action policies. 182 college students, mostly women, who had not been admitted through affirmative action policies participated in the study. Participants completed measures of prejudice, discrimination, and perception of realistic threat and were assigned to one of three experimental conditions: affirmative action appreciation, realistic threat, and control. It was observed that the perception of realistic threat mediated the association between prejudice and discrimination independently of the experimental condition, which indicates the explanatory potential of the JDM for understanding discrimination against affirmative action beneficiaries.
\end{abstract}

Keywords: prejudice, discrimination, Justified Discrimination Model, affirmative action policies

Em 2014, a lei que tornou o racismo crime no Brasil completou 25 anos. Apesar desse e de outros avanços no combate a diferentes tipos de preconceito e discriminação, o problema parece estar longe de ser resolvido. Essa situação permite alguns questionamentos: afinal, por que em sociedades em que a expressão do preconceito e da discriminação é condenada social e juridicamente, como é o caso do Brasil, ainda persistem episódios de discriminação? Além disso, quais elementos disposicionais e contextuais contribuem para a expressão da discriminação? A partir destes questionamentos, o presente artigo tem como objetivo principal apresentar evidências do Modelo da Discriminação Justificada (MDJ; Pereira, Vala, \& Costa-Lopes, 2010; Pereira, Vala, \& Leyens, 2009) como um modelo teórico

1 Apoio: Este projeto foi apoiado por meio de bolsa de produtividade em pesquisa do CNPq do sétimo autor.

2 Endereço para correspondência: Centro Universitário de Brasília (UniCEUB), Faculdades de Ciências da Educação e Saúde (FACES). Campus Asa Norte - Bloco 9, Brasília, DF, Brasil. CEP: 70.790-075. E-mail:jg.modesto@gmail.com que contribui para a compreensão da discriminação na atualidade. Para alcançar esse objetivo, o MDJ será testado como modelo explicativo da discriminação contra estudantes que ingressaram na universidade a partir da política de reserva de vagas (cotas) para negros.

\section{A Persistência da Discriminação e sua Relação com o Preconceito}

O preconceito pode ser entendido como uma reação negativa a um grupo ou a um indivíduo em função de sua pertença a determinado grupo (Allport, 1954; Stangor, 2016), sendo caracterizado como uma atitude negativa com um forte componente afetivo. O preconceito, nesse sentido, envolve um "não gostar" de um indivíduo pelo simples fato deste indivíduo pertencer a determinado grupo. No caso do racismo, esse "não gostar" está associado à inferiorização do negro diante de outras "raças" e, em muitos casos, a um processo de desumanização (Dantas, 2014). Enquanto atitude 
negativa, é possível que o racismo (e os preconceitos em geral) permaneçam encobertos e não se tornem ações explícitas. A discriminação, diferente do preconceito, é, por definição, uma ação aberta, que tem como característica principal um tratamento desigual dado a indivíduos ou grupos diferentes (Baron \& Branscombe, 2012), usualmente envolvendo ações negativas a grupos considerados "minoritários" em determinado contexto social, a exemplo dos negros.

Tendo em vista essas definições, torna-se intuitivo concluir que pessoas com altos índices de preconceito estariam mais propensas a discriminar. A resposta ao questionamento do começo do artigo seria então: a discriminação persiste porque ainda existem pessoas preconceituosas. No entanto, pesquisas na área indicam que a resposta não parece ser tão simples. Embora a relação entre preconceito e discriminação exista, um estudo meta-analítico (Schütz \& Six, 1996) indicou que essa relação é apenas de intensidade média, e que o preconceito não é necessariamente um bom preditor da discriminação.

Uma hipótese que busca explicar essa relação apenas de média intensidade encontrada nas pesquisas, entre preconceito e discriminação, entende que, em função de normas sociais igualitárias, o preconceito tem assumido novas formas (Lima \& Vala, 2004, para uma revisão), ocorrendo uma mudança de um preconceito flagrante para formas mais sutis e escamoteadas de preconceito. Desse modo, medidas de auto-relato, tradicionalmente usadas em pesquisas para avaliar o preconceito, não conseguiriam mensurar o fenômeno de maneira adequada. Os baixos índices de preconceito encontrados nas pesquisas seriam explicados pela presença de normas sociais igualitárias e, consequentemente, da desejabilidade social associada a instrumentos de autorelato. Ou seja, a pessoa pode ser preconceituosa, mas deixar o seu posicionamento encoberto ao participar de pesquisas que administrem medidas explícitas sobre preconceito. Em função desse entendimento, como alternativa ao auto-relato, foram desenvolvidas medidas indiretas para aferição do conteúdo implícito do preconceito, de forma a superar a limitação da desejabilidade social (Trawalter \& Shapiro, 2010), a exemplo do Teste de Associação Implícita (TAI) (Greenwald, Mcghee, \& Schwartz, 1998) e diferentes estratégias de priming (e.g., Devine, 1989; Lima, Machado, Ávila, Lima, \& Vala, 2006; Payne, 2001).

$\mathrm{O}$ uso de medidas indiretas tem permitido avanços na mensuração do preconceito uma vez que a sua avaliação envolve um processamento automático da informação, e a supressão do preconceito ao responder medidas indiretas é mais complexa do que ao responder uma medida explícita (Devine, Plant, Amodio, Harmon-Jones, \& Vance, 2002). Desse modo, medidas indiretas têm conseguido avaliar dimensões do preconceito que não eram acessadas por medidas explícitas (Olson \& Zabel, 2016).

No entanto, o uso de medidas indiretas não é suficiente para explicar a relação entre preconceito e discriminação (Pereira, 2011). Medidas indiretas tendem a predizer reações espontâneas e não ações deliberadas (Dovidio, Kawakami, Johnson, Johnson, \& Howard, 1997), como a discriminação flagrante. Nestes casos, a medida explícita, ainda que possua limitações, tende a ser a melhor alternativa de mensuração
(Stangor, 2016). Um estudo meta-analítico (Oswald, Mitchell, Blanton, Jaccard, \& Tetlock, 2013) indicou que o TAI, principal medida indireta utilizada nos últimos anos (Fazio \& Olson, 2003; Nosek, Hawkins, \& Frazier, 2011), não apresentou melhor poder preditivo que medidas explícitas na explicação da discriminação.

\section{Modelo da Discriminação Justificada}

Considerando a discriminação flagrante como uma ação deliberada, medidas explícitas, por envolverem um processamento controlado da informação, apresentam um melhor potencial preditivo do que medidas indiretas na explicação do fenômeno. Nesse sentido, a resposta ao problema da relação de média intensidade entre preconceito e discriminação não parece ser resolvido com o uso de medidas indiretas. O MDJ (Pereira et al., 2010, 2009) surge como uma alternativa que busca explicar essa relação a partir de argumentos baseados em mecanismos de legitimação (Tyler, 2006) e no processo de ameaça (Stephan, Ybarra, \& Rios, 2016).

Nas últimas décadas, diferentes modelos teóricos têm buscado entender a persistência da discriminação em sociedades em que ela é combatida (Costa-lopes, Dovidio, Pereira, \& Jost, 2013; Ford, Woodzicka, Triplett, Kochersberger, \& Holden, 2014; Ford, 2000; Ford \& Ferguson, 2004; Sidanius, Pratto, Laar, \& Levin, 2004). Esses modelos, em geral, partem do entendimento de que a discriminação é um comportamento contranormativo e de que, para ocorrer, precisa ser legitimada. Este processo envolve o uso de mitos legitimadores que sirvam como justificativas (Sidanius \& Pratto, 2001), tornando a discriminação mais aceita socialmente. Ou seja, se o indivíduo praticar atos discriminatórios, precisa apresentar justificativas (não preconceituosas) que pareçam legítimas e defensáveis em determinado contexto social (Pereira \& Vala, 2010). No Brasil, por exemplo, é comum pessoas contarem piadas racistas e justificarem suas ações como sendo "apenas" uma brincadeira, legitimando assim uma ação discriminatória (Turra \& Venturini, 1995 sobre o papel do humor na discriminação no Brasil).

Partindo dessa hipótese mais geral de legitimação, o MDJ permitiu uma compreensão, não apenas sobre o porquê da persistência da discriminação, mas também sobre os mecanismos que permitem explicar a relação entre preconceito e discriminação. De acordo com o MDJ, as justificativas não permitem apenas um aumento na ocorrência da discriminação em função de sua legitimação, mas representam, também, o mecanismo por meio do qual o preconceito leva à discriminação. Em síntese, em circunstâncias que podem ser apresentadas justificativas que rompam com a norma antipreconceito, pessoas preconceituosas irão discriminar.

O MDJ sustenta-se por duas hipóteses principais. A primeira postula que justificativas atuam como um mediador entre o preconceito e a discriminação. A ideia básica é que justificativas aparentemente não preconceituosas ajudam a esconder a base preconceituosa de um ato discriminatório. Desse modo, o indivíduo supera o desconforto entre sua 
verdadeira atitude (de base preconceituosa) e uma norma social igualitária. A ação passa a ser melhor aceita porque parece basear-se em princípios não preconceituosos, e o preconceito, nesse contexto, passa a ser um melhor preditor da discriminação. Para testar essa hipótese, Pereira et al. (2010) analisaram dados de amostras representativas de 21 países europeus e verificaram que pessoas com altos índices de preconceito discriminavam imigrantes quando utilizavam justificativas com base em uma ameaça real (imigrantes iriam competir por emprego) ou simbólica (imigrantes "destruiriam" a cultura local trazendo seus próprios costumes e valores). Ambos os tipos de ameaça funcionam como justificativas que permitem romper com a norma antipreconceito. Nessas circunstâncias, em função do uso de justificativas, pessoas preconceituosas discriminaram os imigrantes.

A segunda hipótese postulada pelo MDJ afirma que normas sociais funcionam como um moderador da influência da justificativa na relação entre preconceito e discriminação. A ideia é que justificativas só são necessárias quando está saliente uma norma antipreconceito. Quando a norma social favorece a discriminação, a justificativa deixa de ser relevante para explicar a relação entre preconceito e discriminação (Pereira \& Vala, 2007). Por exemplo, em uma reunião de skinheads ninguém precisaria assumir justificativas para praticar ações discriminatórias porque a norma social do grupo favorece esses atos.

Acreditamos que o MDJ permite contribuições para a compreensão da expressão da discriminação em um contexto como o brasileiro, em que prevalecem normas antipreconceito. Nesse sentido, considerando que a discriminação é um problema vivenciado por estudantes que ingressam em instituições públicas pelo sistema de cotas, sobretudo as cotas raciais (Lima, Neves, \& Silva, 2014), o objetivo principal da presente pesquisa foi testar o MDJ como modelo explicativo da discriminação a estudantes que ingressaram em uma universidade pública pelas cotas raciais. Acreditamos que, nas universidades públicas, prevalece uma norma antipreconceito (hipótese 2 do MDJ) e, nessas condições, as justificativas exercerão um importante papel na explicação da discriminação (hipótese 1 do MDJ).

\section{A política de Cotas em Instituições de Ensino Público no Brasil e a Discriminação a Cotistas}

As primeiras experiências de cotas em instituições de ensino público no Brasil datam de 2003, embora seja alvo de debates em movimentos sociais desde a década de 1980 (Telles, 2003). A ideia que sustenta a política de cotas no Brasil é de uma reparação a grupos historicamente desfavorecidos, como os negros.

A implementação das primeiras experiências no país se deu por iniciativa de universidades públicas, por meio de seus Conselhos Universitários. O conselho de cada instituição tinha autonomia para deliberar sobre o percentual de vagas reservadas. Desde estas experiências pioneiras, houve grupos contrários à política de cotas que fomentaram debates sobre a constitucionalidade dessa reserva de vagas (Melo, Dantas, Fernandez, Pereira, \& Chaves, 2014). Usualmente, os posicionamentos contrários às cotas tendem a se centrar em argumentos meritocráticos de que a reserva de vagas fere o princípio da igualdade, de justiça social entre os indivíduos e de que as cotas não seriam suficientes para resolver o problema da exclusão social (Neves \& Lima, 2007; Silva \& Silva, 2012).

Apesar de setores contrários, em 2012, foi sancionada a lei das cotas. A lei garante a reserva de $50 \%$ das vagas de institutos federais de educação e universidades públicas para alunos que cursaram integralmente o ensino médio em escolas públicas. Destes 50\%, metade das vagas é destinada para alunos com renda familiar igual ou inferior a um salário mínimo e meio per capita, sendo a outra metade destinada aos estudantes com renda familiar superior a este valor. Do total de vagas reservadas, há um percentual mínimo (de acordo com o censo do IBGE na região) que deve se destinar a negros, pardos e indígenas.

Embora a lei favoreça o acesso às instituições de ensino, isso não significa que o debate sobre as cotas se encerrou. A garantia jurídica ao acesso é apenas o primeiro passo, sendo necessário um conjunto de ações afirmativas adicionais que favoreçam a permanência desses alunos em condições dignas.

Um importante ponto sobre a permanência e condições dignas destes estudantes se refere à discriminação sofrida em ambiente universitário pelos cotistas (Nery \& Costa, 2009; Silva \& Silva, 2012). Acreditamos que embora tenham sido investigados diferentes aspectos que se relacionam com a discriminação a cotistas, a exemplo das estratégias de enfrentamento dos cotistas frente à discriminação (Nery \& Costa, 2009), das representações sociais sobre cotistas e sistema de cotas (Melo et al., 2014; Silva \& Silva, 2012), do efeito da ameaça dos estereótipos no desempenho acadêmico dos cotistas (Silva \& Pereira, 2009), pouca atenção tem sido dada aos processos que legitimam a discriminação contra o cotista (Lima et al., 2014 como uma exceção).

A presente pesquisa buscou então suprir essa lacuna na literatura, tendo como objetivo principal testar o MDJ no contexto da discriminação a cotistas. Para alcançar esse objetivo, avaliamos duas questões principais. Primeiramente testamos a hipótese de mediação do MDJ: justificativas com base em uma percepção de ameaça real (a qualidade do ensino da instituição diminuiu com a política de cotas) atuam como mediador da relação entre preconceito e discriminação. Optamos por utilizar a ameaça real como justificativa por se coadunar com os postulados do MDJ, e também devido à importância da ameaça real na investigação da atitude em relação a cotas (Lima et al., 2014). A análise desta primeira hipótese permite evidências sobre o potencial de generalização do MDJ para explicar a discriminação em outros contextos (discriminação a cotistas) e outras culturas (dados coletados no Brasil).

Buscamos avaliar a extensão do papel exercido pela ameaça real como legitimador da discriminação, ao invés de testar apenas a percepção da ameaça (o que envolve uma avaliação disposicional a partir de medida de diferenças individuais), buscamos manipular a presença da ameaça (o que envolve uma ativação situacional), e descrever sua influência na relação entre preconceito e discriminação. Formulamos uma hipótese de moderação em que a apresentação situacional da ameaça (e não apenas 
sua percepção) pode influenciar a relação entre preconceito e discriminação. Entendemos que o teste do efeito da apresentação situacional da ameaça está de acordo com os pressupostos do MDJ, já que pode servir como uma justificativa para o indivíduo no momento da discriminação (Pereira, Torres, \& Almeida, 2003), permitindo implicações para a compreensão dos processos de legitimação, na medida em que avalia se a ameaça real é algo estruturado e já estabelecido na cognição do indivíduo ou se ativações situacionais são suficientes para estabelecer condições para legitimar a discriminação. A adaptação proposta, somada à hipótese original, permitirá compreender a extensão do modelo em função da avaliação da ameaça por diferentes estratégias: a partir da mensuração da percepção e de uma ativação situacional.

\section{Método}

\section{Participantes}

Participaram do estudo 210 estudantes universitários de uma universidade pública, sendo que 23 participantes ingressaram na universidade por meio da política de reserva de vagas e 5 participantes não informaram a modalidade de ingresso na instituição. Esses 28 estudantes foram excluídos da amostra já que o objetivo foi avaliar a discriminação a cotistas, sendo mais adequada que a avaliação seja feita por membros do exogrupo. Dos 182 casos válidos, 76,85\% eram do sexo feminino, com idades variando de 16 a 46 anos $(M$ $=20,70 ; D P=4,48)$. Os participantes foram distribuídos, de maneira aleatória, em três condições experimentais: apresentação das cotas como uma ameaça (62 participantes), valorização das cotas (56 participantes) e grupo controle (64 participantes).

\section{Instrumentos}

Para avaliar o preconceito dos participantes, foi utilizada a Escala de Racismo Moderno (McConahay, 1986) adaptada ao contexto brasileiro (Santos, Gouveia, Navas, Pimentel, \& Gusmão, 2006). A medida tem como objetivo avaliar o racismo de forma mais sutil e escamoteada. A escala é composta por 14 itens (e.g., "Eles têm conseguido mais do que merecem", "Possuem uma beleza diferente") que devem ser avaliados em escala likert que varia de 1 (discordo totalmente) até 7 (concordo totalmente). No estudo de adaptação, foram encontrados dois fatores principais: negação do preconceito $(\alpha=0,71)$ e afirmação das diferenças $(\alpha=0,74)$. No presente estudo, a medida apresentou consistência interna satisfatória, com alfa de Cronbach de 0,79 para o primeiro fator e 0,71 para o segundo.

Assim como em estudos anteriores (Pereira et al., 2010, 2009), utilizamos medidas de auto-relato para avaliar a discriminação, em função da dificuldade e de questões éticas envolvidas na mensuração de um comportamento discriminatório propriamente dito. Foram utilizados cinco itens ("Me sinto confortável em relação às cotas raciais",
"Para mim, as cotas raciais são desnecessárias", "Acredito que as cotas raciais estão contribuindo para a democratização das universidades públicas", "Eu sou a favor das cotas raciais", "Defenderia publicamente as cotas raciais"), que agrupados também apresentaram consistência interna satisfatória $(\alpha=0,90)$.

Para avaliar a percepção das políticas afirmativas como uma ameaça real para a universidade foi utilizado um item ("Você, como estudante desta universidade, acredita que a qualidade da instituição diminuiu após a implementação da política de cotas raciais?"). A ideia de ameaça real neste caso envolve o entendimento que a redução da qualidade do ensino, em função da política de cotas, prejudica todos os estudantes. Esse entendimento está de acordo com o conceito de ameaça real utilizado em outros estudos (Stephan et al., 2016). Escolhemos esse tipo de ameaça por ser comum o uso de argumentos dessa natureza na oposição às cotas.

Para a manipulação experimental da ameaça, foi apresentado um cenário no formato de uma suposta notícia de jornal. A partir da notícia, buscamos manipular três condições experimentais: presença da ameaça (era informado que a qualidade das instituições públicas foi reduzida após a entrada dos estudantes cotistas), valorização (era informado que a qualidade das instituições públicas aumentou após a entrada dos estudantes cotistas) e controle (notícia neutra sobre as instituições públicas).

\section{Procedimentos}

O presente estudo seguiu todos os princípios éticos previstos pela American Psychological Association. Entre outros aspectos, foi apresentado o termo de consentimento, onde informamos sobre a garantia de anonimato e confidencialidade das informações prestadas (questionários não identificados individualmente, análises agrupadas e uso das informações para fins de relatos científicos), os propósitos da pesquisa, expectativa de duração da coleta, procedimentos a serem realizados, contatos dos pesquisadores responsáveis pelo estudo e que o estudante poderia rejeitar em participar (ou abandonar o estudo já iniciado) sem que incorresse em nenhuma sanção.

Para a realização da pesquisa, estudantes universitários foram convidados a participar do estudo de maneira voluntária. Caso aceitassem, assinavam o termo de consentimento e eram direcionados para uma sala reservada para a coleta de dados. O participante recebia um questionário em papel que continha a suposta notícia (manipulação experimental) e os demais itens a serem avaliados. A alocação por condição foi feita de maneira aleatória. Após a conclusão da pesquisa, o participante recebia o debriefing, em que eram explicadas as hipóteses da pesquisa, a proposta teórica do MDJ e informado que a notícia apresentada era falsa. Após estes esclarecimentos, era dada novamente a possibilidade que o estudante declinasse de sua participação. No entanto, nenhum participante solicitou exclusão do estudo. 


\section{Resultados}

Para o teste de mediação, foram realizadas regressões lineares considerando toda a amostra, independente da condição experimental, e em seguida conduzido o Teste de Sobel. A partir de uma regressão linear, verificou-se que o preconceito explica $18 \%$ da variância da percepção de ameaça real, $\beta=0,42, t(179)=6,25, p<0,001$ (caminho AVer Figura 1), indicando que pessoas com maiores índices de preconceito racial tendem a perceber as políticas afirmativas como uma ameaça real. Conduzindo uma nova regressão linear, verificou-se que a percepção de ameaça explica $22 \%$ da discriminação, $\beta=0,50, t(178)=7,08, p<0,001$ (caminho B), o que significa que pessoas que percebem as políticas afirmativas como uma ameaça tendem a apresentar maiores índices de discriminação. Novamente por meio de uma regressão linear, verificou-se que o preconceito racial explica $12 \%$ da variância da discriminação, $\beta=0,35, t(180)$ $=5,04, p<0,001$ (caminho C), indicando que pessoas com maiores índices de preconceito racial apresentaram maiores índices de discriminação a cotistas.

Uma vez encontrados os efeitos diretos em cada um dos "caminhos", conduzimos um Teste de Sobel a fim de testar a hipótese de mediação. Verificou-se que a percepção da ameaça real é um mediador na relação entre preconceito racial e discriminação a cotistas, como indicado pelo Teste de Sobel,

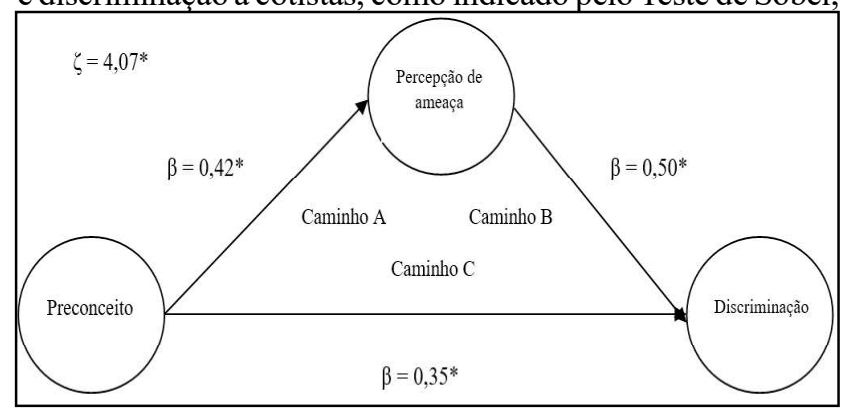

Figura 1. Parâmetros estatísticos do modelo de mediação Nota. $* p<0,001$

$\zeta=4,07, p<0,001$, corroborando a hipótese postulada. Este resultado indica que pessoas com altos índices de preconceito tendem a perceber as políticas afirmativas como uma ameaça e então há uma maior probabilidade de discriminar os cotistas. A relação de mediação indica que, quando considerada a percepção de ameaça real, o preconceito se torna um melhor preditor da discriminação. A Figura 1 apresenta o modelo de mediação testado com os parâmetros estatísticos.

Por meio da ANOVA, testamos o efeito direto da manipulação da presença da ameaça real na discriminação, não sendo encontrados resultados significativos, $F(2,179)=$ $0,03, p=0,974, \eta^{2} p=0,001$.

A partir de regressões lineares realizadas separadamente para os participantes de cada condição experimental, testamos a proposta de adaptação do MDJ, na qual propusemos uma hipótese de moderação da apresentação situacional da ameaça na relação entre preconceito e discriminação. Verificou-se que o preconceito teve um efeito positivo na discriminação na condição de valorização das cotas, $\beta=0,35, t(60)=2,90, p=$ 0,005 , na condição de ameaça real, $\beta=0,37, t(54)=2,95, p=$ 0,005 e na condição controle, $\beta=0,34,(62)=2,89, p=0,005$. Independente de uma ativação situacional, houve um efeito positivo do preconceito na discriminação, indicando ausência de efeito de moderação, diferente da hipótese formulada.

\section{Discussão}

A presente pesquisa teve como objetivo principal investigar o MDJ no contexto da discriminação a cotistas. Para alcançar esse objetivo, testamos uma hipótese de mediação que afirmava que a percepção da ameaça real atua como um mediador da relação entre preconceito e discriminação. Adicionalmente, avaliamos uma hipótese de moderação que pressupunha um efeito de moderação de uma ativação situacional da ameaça real na relação entre preconceito e discriminação.

A hipótese de mediação foi corroborada: a percepção da ameaça real atuou como um mediador na relação entre preconceito e discriminação. Pessoas com maiores índices de preconceito avaliaram o ingresso dos estudantes cotistas na universidade como uma ameaça real ao afirmarem que a política de cotas contribuía para a diminuição da qualidade do ensino na universidade. Uma vez de posse desta justificativa, participantes com altos índices de preconceito discriminavam os cotistas. Corroborando a hipótese de mediação, quando testada a influência direta do preconceito na discriminação, o efeito foi menor do que quando consideradas as justificativas como um mediador dessa relação. Estes achados estão de acordo com os postulados do MDJ (Pereira et al., 2010, 2009), das teorias que aludem a diferentes processos de legitimação (Tyler, 2006), bem como das teorias que discutem o papel exercido por noções de ameaça nas relações intergrupais (Stephan et al., 2016). Em um contexto em que prevalece uma norma antipreconceito, como é o caso do Brasil, sobretudo em universidades públicas, o uso de justificativas parece exercer um importante papel na legitimação da discriminação, bem como contribui com a compreensão da relação entre preconceito e discriminação. Nesse sentido, pessoas com altos índices de preconceito tendem a apresentar maiores índices de discriminação quando é possível o uso de justificativas aparentemente não preconceituosas. O uso de justificativas rompe com a norma antipreconceito, e nessas circunstâncias pessoas preconceituosas tendem a discriminar mais.

A segunda hipótese testada não foi corroborada. Acreditávamos que uma ativação situacional da ameaça seria suficiente para interferir na relação entre preconceito e discriminação. Verificou-se que a manipulação da apresentação das cotas como uma ameaça real não levou a uma maior discriminação se comparado à condição que valorizava a política de cotas ou a um grupo controle. Independente da manipulação experimental, o preconceito apresentou um efeito semelhante na explicação da discriminação. Esse achado chama atenção para a importância em diferenciar a percepção da ameaça com a existência da ameaça. Um estudo que comparou a real presença de imigrantes na Alemanha, com a percepção da proporção de imigrantes nesta população, verificou que apenas esta última, e não a primeira, influenciou atitudes de exclusão (Semyonov, Raijman, Tov, \& Schmidt, 2004). Ao que tudo indica, conforme apontam também nossos resultados, a expectativa sobre ameaça parece ser 
uma variável mais relevante se comparada à existência real da ameaça, para produzir o efeito esperado.

O teste das duas hipóteses, se analisadas em conjunto, parece indicar que o uso da justificativa na legitimação da discriminação envolve um processo de maior elaboração e reflexão do que uma mera ativação situacional, entendimento que se relaciona com a importância dada aos processos controlados na explicação da discriminação flagrante (Oswald et al., 2013). Nesse sentido, as pessoas parecem estar conscientes de seu preconceito, e têm clareza que o uso de determinadas justificativas permite a expressão da discriminação, já que esta passa a ser legitimada por argumentos supostamente não preconceituosos. Na situação investigada, a ativação situacional de valorização ou crítica da política de cotas não influenciou os participantes. A opinião que os participantes já tinham, a princípio, sobre a política de cotas parece ser fruto de um processo de elaboração e reflexão que se sobrepôs à ativação situacional. Essa opinião formada anteriormente (e não apenas uma oferta de informação situacional) serviu como justificativa influenciando na discriminação aos cotistas.

Algumas limitações do presente estudo devem ser ressaltadas. Utilizamos apenas a noção de ameaça real como possibilidade de justificativa para os participantes. Novas pesquisas podem utilizar outras possibilidades de justificativa, como, por exemplo, o uso do humor e de piadas (Ford \& Ferguson, 2004; Ford et al., 2014) que parecem ser uma justificativa comum no país para legitimar o racismo (Turra \& Venturini, 1995). Outro aspecto da pesquisa que merece ressalva é o uso de itens que medem a oposição a cotas como uma medida de discriminação. Embora saibamos da limitação da medida, por não se tratar propriamente de uma ação (pressuposto do conceito de discriminação), acreditamos que esse é o formato de questão que melhor permite que nos aproximemos de nosso objeto de estudo. No entanto, novos estudos podem considerar outras maneiras de mensurar e avaliar o fenômeno.

A presente pesquisa permite algumas contribuições. Em relação a uma dimensão teórica, verificam-se evidências de validade do MDJ para explicação da discriminação de outros grupos (cotistas) em outros contextos culturais (Brasil). Evidências transculturais permitem avaliar o potencial de generalização de modelos teóricos, o que tem sido considerado relevante na ciência psicológica, sobretudo em psicologia social, uma vez que a maior parte da produção na área se refere a estudos desenvolvidos nos Estados Unidos (Henrich, Heine, \& Norenzayan, 2010; Smith, Fischer, Vignoles, \& Bond, 2013).

Este estudo também contribui em uma dimensão aplicada. Por um lado, uma vez identificado que justificativas com base em uma ameaça real (cotas raciais contribuiriam para a queda na qualidade de ensino) legitimam a discriminação contra cotistas, conclui-se que o combate à discriminação pode passar por um combate a essas justificativas. Por outro lado, verificou-se que a percepção do indivíduo, e não dados situacionais, foi responsável pelo efeito encontrado. Isso indica que o combate a essas justificativas não deve ser episódico, mas ocorrer de maneira contínua. Nesse sentido, é possível, por exemplo, estimular uma divulgação constante de resultados que indiquem que em muitos cursos não há diferenças significativas no desempenho acadêmico de estudantes cotistas e não-cotistas, bem como que não houve redução dos índices de produtividade e qualidade das instituições pós-implementação das cotas (Queiroz \& Santos, 2006; Velloso, 2009 como exemplos). Acreditamos que uma exposição regular desses resultados pode contribuir para que, a longo prazo, essas justificativas não sejam mais aceitas como argumentos que favoreçam a legitimação da discriminação.

\section{Referências}

Allport, G. W. (1954). The nature of prejudice. Reading, MA: Addison-Wesley.

Baron, R. A., \& Branscombe, N., R. (2012). Social psychology (13nd Edition). New York: Pearson.

Costa-Lopes, R., Dovidio, J. F., Pereira, C. R., \& Jost, J. T. (2013). Social psychological perspectives on the legitimation of social inequality: Past, present and future. European Journal of Social Psychology, 43, 229-237. doi:10.1002/ejsp.1966

Dantas, G. S. (2014). Efeitos de primings de crime na identificação de armas, no racismo, na desumanização e na atribuição de punição (Dissertação de mestrado não publicada). Retrieved from http://www.pospsi.ufba.br/Gilcimar_Dantas.pdf

Devine, P. G. (1989). Stereotypes and prejudice: Their automatic and controlled components. Journal of Personality and Social Psychology, 56, 5-18. doi: http://dx.doi.org/10.1037/00223514.56.1.5

Devine, P. G., Plant, E. A., Amodio, D. M., Harmon-Jones, E., \& Vance, S. L. (2002). The regulation of explicit and implicit race bias: The role of motivations to respond without prejudice. Journal of Personality and Social Psychology, 82, 835-848. doi: http://dx.doi.org/10.1037/0022-3514.82.5.835

Dovidio, J. F., Kawakami, K., Johnson, C., Johnson, B., \& Howard, A. (1997). On the nature of prejudice: Automatic and controlled processes. Journal of Experimental Social Psychology, 540, 510-540. doi:JS971331

Fazio, R. H., \& Olson, M. a. (2003). Implicit measures in social cognition. Research: Their meaning and use. Annual Review of Psychology, 54, 297-327. doi:10.1146/annurev. psych.54.101601.145225

Ford, T. E. (2000). Effects of sexist humor on tolerance of sexist events. Personality and Social Psychology Bulletin, 26, 1094-1107. doi:10.1177/01461672002611006

Ford, T. E., \& Ferguson, M. A. (2004). Social consequences of disparagement humor: A prejudiced norm theory. Personality and Social Psychology Review, 8, 79-94. doi:10.1207/ S15327957PSPR0801_4

Ford, T. E., Woodzicka, J. A., Triplett, S. R., Kochersberger, A. O., \& Holden, C. J. (2014). Not all groups are equal: Differential vulnerability of social groups to the prejudice-releasing effects of disparagement humor. Group Processes \& Intergroup Relations, 17, 178-199. doi:10.1177/1368430213502558

Greenwald, A. G., Mcghee, D. E., \& Schwartz, J. L. K. (1998). Measuring individual differences in implicit cognition: The implicit association test. Journal of Personality and Social Psychology, 74, 1464-1480. doi:http://dx.doi. org/10.1037/0022-3514.74.6.1464 
Henrich, J., Heine, S. J., \& Norenzayan, A. (2010). The weirdest people in the world? The Behavioral and Brain Sciences, 33, 61-83. doi:http://doi.org/10.1017/S0140525X0999152X

Lei $\mathrm{n}^{\circ} 7.716$ de 05 de janeiro 1989. (1989). Define os crimes resultantes de preconceito de raça ou de cor. Diário Oficial da União.

Lei $\mathrm{n}^{\circ} 12.711$ de 29 de agosto 2012. (2012). Dispõe sobre o ingresso nas universidades federais e nas instituições federais de ensino técnico de nível médio e dá outras providências. Diário Oficial da União.

Lima, M. E. O., Machado, C., Ávila, J., Lima, C., \& Vala, J. (2006). Normas sociais e preconceito: O impacto da igualdade e da competição no preconceito automático contra os negros. Psicologia: Reflexão e Crítica, 19, 309-319. doi:http://dx.doi. org/10.1590/S0102-79722006000200018

Lima, M. E. O., Neves, P. S. da C., \& Silva, P. B. E. (2014). A implantação de cotas na universidade: Paternalismo e ameaça à posição dos grupos dominantes. Revista Brasileira de Educação, 19, 141-163. Retrieved from: http://www.redalyc. org/articulo.oa? id $=27530123008$

Lima, M. E. O., \& Vala, J. (2004). As novas formas de expressão do preconceito e do racismo. Estudos de Psicologia, 9, 401-411. doi:http://dx.doi.org/10.1590/S1413-294X2004000300002

McConahay, J. B. (1986). Modern racism, ambivalence, and the modern racism scale. In J.F. Dovidio \& S. L. Gaertner (Eds.), Prejudice, discrimination, and racism (pp. 91-125). San Diego: Academic.

Melo, C. V. G., Dantas, G. S., Fernandez, Z. M. B., Pereira, M. E., \& Chaves, A. M. (2014). Representações sociais de estudantes da UFBA sobre as cotas universitárias. Psicologia e Saber Social, 3(1), 55-69. Retrieved from http://www.e-publicacoes.uerj.br/ index.php/psi-sabersocial/article/view/9482

Nery, M. da P., \& Costa, L. F. (2009). Afetividade entre estudantes e sistema de cotas para negros. Paideia, 19(43), 257-266. Retrieved from http://www.redalyc.org/articulo. oa? id $=305423765014$

Neves, P. S. C., \& Lima, M. E. O. (2007). Percepções de justiça social e atitudes de estudantes pré-vestibulandos e universitários sobre as cotas para negros e pardos nas universidades públicas. Revista Brasileira de Educação, 12(34), 17-38. Retrieved from http://www.scielo.br/pdf/\%0D/rbedu/v12n34/a03v1234.pdf

Nosek, B. A., Hawkins, C. B., \& Frazier, R. S. (2011). Implicit social cognition: From measures to mechanisms. Trends in Cognitive Sciences, 15, 152-9. doi:http://dx.doi.org/10.1016/j. tics.2011.01.005

Olson, M. A., \& Zabel, K. L. (2016). Measures of prejudice. In T. D. Neslon (Ed.), Handbook of prejudice, stereotyping and discrimination (pp. 175-212). New York: Psychology Press.

Oswald, F. L., Mitchell, G., Blanton, H., Jaccard, J., \& Tetlock, P. E. (2013). Predicting ethnic and racial discrimination: A metaanalysis of IAT criterion studies. Journal of Personality and Social Psychology, 105, 171-92. doi:http://dx.doi.org/10.1037/ a0032734

Payne, B. K. (2001). Prejudice and perception: The role of automatic and controlled processes in misperceiving a weapon. Journal of Personality and Social Psychology, 81, 181-192. doi: http:// dx.doi.org/10.1037/0022-3514.81.2.181
Pereira, C. (2011). A legitimação da discriminação em diferentes contextos normativos. In E. M. Techio \& M. E. O. Lima (Eds.), Cultura e produção das diferenças: Estereótipos e preconceito no Brasil, Espanha e Portugal (pp. 363-404). Brasília: Technopolotik.

Pereira, C. R., \& Vala, J. (2010). Do preconceito à discriminação justificada. In-Mind_Português, 1(2-3), 1-13. Retrieved from http://bibliobase.sermais.pt:8008/BiblioNET/upload/ PDF2/01159_pereira_e_vala_2010.pdf

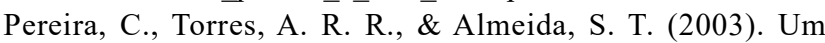 estudo do preconceito na perspectiva das representações sociais: Análise da influência de um discurso justificador da discriminação no preconceito racial. Psicologia: Reflexão e Crítica, 16(1), 95-107. doi: http://dx.doi.org/10.1590/S010279722003000100010

Pereira, C., \& Vala, J. (2007). Preconceito, normas sociais e justificações para a discriminação de pessoas de cor negra. In J. Vala, M. Garrido, \& P. Alcobia (Eds.), Percursos da investigação em psicologia social e organizacional (2nd ed., Vol. II, pp. 145-164). Lisboa: Edições Colibri.

Pereira, C., Vala, J., \& Costa-Lopes, R. (2010). From prejudice to discrimination: The legitimizing role of perceived threat in discrimination against immigrants. European Journal of Social Psychology, 40, 1231-1250. doi:10.1002/ejsp

Pereira, C., Vala, J., \& Leyens, J. P. (2009). From infra-humanization to discrimination: The mediation of symbolic threat needs egalitarian norms. Journal of Experimental Social Psychology, 45, 336-344. doi: http://dx.doi.org/10.1016/j.jesp.2008.10.010

Queiroz, D. M., \& Santos, J. T. (2006). Sistema de cotas: Um debate dos dados à manutenção de privilégios e de poder. Educação e Sociedade, 27(96), 717-737. Retrieved from: http://www. scielo.br/pdf/\%0D/es/v27n96/a05v2796.pdf

Santos, W. S., Gouveia, V. V., Navas, M. S., Pimentel, C. E., \& Gusmão, E. É. da S. (2006). Escala de racismo moderno: Adaptação ao contexto brasileiro. Psicologia em Estudo, 11, 637-645. doi: http://dx.doi.org/10.1590/S141373722006000300020

Schütz, H., \& Six, B. (1996). How strong is the relationship between prejudice and discrimination? A meta-analytic answer. Journal of Intercultural Relations, 20, 441-462. doi:10.1016/01471767(96)00028-4

Sidanius, J., \& Pratto, F. (2001). Social dominance: An intergroup theory of social hierarchy and oppression. London: Cambridge University Press.

Sidanius, J., Pratto, F., Laar, C. Van, \& Levin, S. (2004). Social Dominance Theory: Its agenda and method. Political Psychology, 25, 845-880. doi: 10.1111/j.14679221.2004.00401.x

Silva, J. F. da, \& Pereira, M. E. (2009). Ameaça dos estereótipos no desempenho intelectual de estudantes universitários cotistas. In J. A. C. Lordelo \& M. V. Dazzani (Eds.), Avaliação educacional: Reatando e desatando nós (pp. 225-247). Salvador: EDUFBA. Retrieved from: http://books.scielo.org/ $\mathrm{id} / \mathrm{wd} / 11$

Silva, P. B. E., \& Silva, P. da. (2012). Representação social de estudantes universitários sobre cotas nas universidades. Fractal: Revista de Psicologia, 24, 525-542. Retrieved from: http://www.uff.br/periodicoshumanas/index.php/Fractal/ article/view/517 
Smith, P. B., Fischer, R., Vignoles, V. L. \& Bond, M. H. (2013) Understanding social psychology across cultures: Engaging with others in a changing world. 2nd Edition. London: Sage.

Semyonov, M., Raijman, R., Tov, A. Y., \& Schmidt, P. (2004). Population size, perceived threat, and exclusion: A multipleindicators analysis of attitudes toward foreigners in Germany. Social Science Research, 33, 681-701. doi: http://dx.doi. org/10.1016/j.ssresearch.2003.11.003

Stangor, C. (2016). The study of stereotyping, prejudice, and discrimination within social psychology: a quick history of theory and research. In T. D. Neslon (Eds.), Handbook of prejudice, stereotyping and discrimination (pp. 3-27). New York: Psychology Press.
Stephan, W. G., Ybarra, O., \& Rios, K. (2016). Intergroup Threat Theory. In T. D. Neslon (Eds.), Handbook of prejudice, stereotyping and discrimination (pp. 255-278). New York: Psychology Press.

Telles, E. (2003). Racismo à brasileira: Uma nova perspectiva sociológica. Rio de Janeiro: Relume Dumará, Fundação Ford.

Trawalter, S \& Shapiro, J. R. (2010). Racial bias and stereotyping: interpersonal processes. In B. Gawronski \& K. Payne (Eds.), Handbook of implicit social cognition (pp. 375-391). New York: The Guilford Press.

Turra, C., \& Venturi, G. (1995). Racismo cordial: A mais completa análise sobre preconceito de cor no Brasil. São Paulo: Ática.

Tyler, T. R. (2006). Psychological perspectives on legitimacy and legitimation. Annual Review of Psychology, 57, 375-400. doi:10.1146/annurev.psych.57.102904.190038

Velloso, J. (2009). Cotistas e não-cotistas: Rendimentos de alunos na Universidade de Brasília. Cadernos de Pesquisa, 39, 621-644. Retrieved from: http://publicacoes.fcc.org.br/ojs/index.php/ $\mathrm{cp} /$ article/view/240 